\title{
The International Primary Care Respiratory Group COPD award
}

\section{Thys van der Molen}

Launched at the International Primary Care Respiratory Group (IPCRG) conference 2002, The COPD Award is an initiative to improve the diagnosis and management of Chronic Obstructive Pulmonary Disease through the sharing of best practice at a primary care level.

Thys van der Molen, Immediate Past President of the IPCRG discusses the importance of rewarding primary care practitioners who have developed successful COPD management strategies, and the benefits of sharing best practice.

"From a patient perspective, a critical factor in learning to live with COPD is having a supportive and understanding General Practitioner"

COPD Patient, United Kingdom

Entering for the award is very straightforward. There is a standard application form which you can download from the IPCRG website http://www.ipcrg.org or you can request a copy from

The COPD Award

Secretariat

Unit 6,49 Atalanta Street,

London SW6 6TR,

Email:

Copd.Award@tshg.com

Please note that the deadline for entries has been extended to the 31 st March 2002.

\section{Thys van der Molen}

Correspondence to:

Unit 6,49 Atalanta Street, London SW6 6TR,

Email:

Copd.Award@tshg.com

Date submitted: $28 / 10 / 02$

Date Accepted: 08/11/02

Prim Care Resp J 2002: 11(4);130
$\mathrm{T}$ he COPD Award seeks to make a positive impact on COPD, through rewarding, encouraging, developing and sharing best practice management of COPD at a primary care level.

Launched by the IPCRG earlier this year, The COPD Award is the first international scheme to recognise excellence in primary care management of this disease. Through the award, the IPCRG seeks to raise awareness of successful COPD management strategies, thus recognising the central role of General Practitioners in tackling this disease.

As we are all aware respiratory diseases, in particular COPD, are an immense burden to healthcare systems, comprising a significant component of both acute and chronic workload. We all know the pressure that this puts on our practices. In fact, the burden of respiratory illness in some countries is such that the respiratory-related consultations in busy primary care practices can equal or exceed the number of outpatient consultations of a pulmonary specialist in a general hospital.

New awareness initiatives, such as World COPD Day run through GOLD (Global initiative for Obstructive Lung Disease) have the potential to increase patient consultation. Therefore it is more important than ever that we act together to improve our treatment strategies and share our knowledge with other members of the primary care community.

To win the award practices should demonstrate successful diagnosis and treatment of COPD by following international guidelines. Patients should be encouraged to participate actively in the management of their condition. The award judges will also consider methods of staff development for successful COPD management and encouraging patients (particularly those at-risk) to consult their doctor.

As you read this article, if you can think of patients whom you have helped understand and live with COPD, and are able to provide examples of good
COPD management in your own practice, such as initiatives to improve patient presentation and diagnosis, or attempts to reduce exacerbations, I invite you to share your experiences by entering the award. You will need to share specific situation(s) where management of COPD at the primary care level has helped your patient(s). All of us who contribute to and regularly read the Primary Care Respiratory Journal do so because we have an interest in lung disease and how we can improve the lives of our respiratory patients. Sharing these experiences is a key step towards improving COPD management, which has real benefits for us as primary care practitioners and for our patients.

Through this scheme, and with your participation, we can help raise standards in COPD care. Together we can share our best practice to help those millions of people who suffer this debilitating disease.

\section{Applications for The COPD Award}

Participants are invited to submit a manuscript of up to a maximum of 1,000 words, in English, outlining their own best practice relating to COPD diagnosis, treatment or management. The manuscript should focus on any single area, or combination, involving diagnosis, treatment, management or information sharing. We would encourage you to show implementation of the GOLD treatment principles in your work.

The top three practitioners, as judged by an international panel, will be sponsored to attend the 2003 European Respiratory Society Conference in Vienna, Austria. At the conference there will be an opportunity for the winners to share best practice knowledge within COPD primary care seminars.

The Award is open to all practitioners who are involved with COPD diagnosis, management and treatment at primary care level and who have direct contact with COPD patients.

The IPCRG works to improve respiratory care in general practice through research, education and development in collaboration with others interested in respiratory care. In addition, the IPCRG aims to stimulate respiratory care research in primary care; improve international collaboration between respiratory groups and raise awareness of respiratory issues worldwide. The IPCRG is an independent organisation of Primary Care Physicians. It receives educational grants from several pharmaceutical companies. The COPD Award is wholly supported by an unrestricted educational grant from Boehringer Ingelheim. 